\title{
Impacto del Capítulo XI del TLCAN (inversiones) en el Medio Ambiente Nacional.
}

\section{Impact of the 11th chapter of NAFTA (investments) in the national environment.}

\section{Eusebio Flores Barraza ${ }^{1}$}

Sumario: Introducción. I. Arbitraje Comercial Internacional. II. El mecanismo del CIADI. III. Arreglo de diferencias según el Capítulo XI del TLCAN. IV. Caso Metalclad vs México. V. Conclusiones.

\section{Resumen.}

Una de las condiciones para celebrar el tratado de libre comercio entre USA, CA y MX, fue igualar y hacer una armonización de la legislación interna entre los Estados parte. Sin embargo, en el TLCAN, en materia ambiental no se dio esta armonización entre las partes, sino que se creó un acuerdo por separado, con poder limitado para implementar estándares obligatorios. En el TLCAN, lo que es denominado "libre comercio", es en realidad una combinación de nuevas protecciones corporativas, tarifas reducidas y nuevas regulaciones complejas de comercio.

Al liberar el comercio en una región se ve afectado el medio ambiente, ya que se aumenta la producción de bienes, se alteran los métodos de producción, y se generan desperdicios, que la mayoría de las veces son tóxicos. En México, el daño es evidente, desde la disminución de calidad del aire, los ríos contaminados, hasta los lugares donde debido a la pobre aplicación de la ley, empresas nacionales e internacionales destruyeron el suelo y contaminaron el subsuelo con desechos tóxicos. Igualmente en este artículo analizamos un caso práctico: Metalclad vs México, en el cual se ve involucrada la aplicación del de la normatividad ambiental e inversiones extranjeras.

\begin{abstract}
.
A precondition in free trade treaties is that in order to level the playing field, an harmonization of the domestic laws between the countries is necessary. However, in the NAFTA, on environmental matters, this harmonization between the parties did not happen, instead, another treaty was signed, one with limited power to implement regulatory standards. In NAFTA, what is termed "free trade", is none other than a combination of new corporate protections, lower rates and complex new trade regulations.

The reduction of barriers on free trade will affect the environment, because of the increased production of goods, the change in production techniques and the waste this generates, which most of the time is toxic. In Mexico, the damage is evident, from the diminishing air quality, the contaminated rivers, to the places where due to the poor application of the law, national and international companies have destroyed the soil and
\end{abstract}

\footnotetext{
${ }^{1}$ Docente-Investigador de TC del Departamento de Derecho de la Universidad de Sonora, DCS, URC, Doctor en Derecho por la Universidad de La Habana, Cuba, doctoreusebioippson@live.com.mx
} 
tainted the subsoil with their toxic waste. Also in this paper we analyze a case: Metalclad vs Mexico, where the application of environmental regulations and foreign investment is involved.

\section{Resumé.}

Une condition pour la célébration de l'accord de libre-échange entre les États-Unis, le Canada et le Mexique, est égaliser et harmoniser les lois internes des États parties. Toutefois, dans l'ALÉNA, sur l'environnement il n'y a pas été cette harmonisation, mais il s'est créé un accord distinct avec une puissance limitée de mettre en œuvre des normes obligatoires. Dans l'ALÉNA, lequel on appelle "le libre-échange", il est en fait, une combinaison de nouvelles protections d'entreprise, taux bas et de nouvelles réglementations commerciales complexes.

La réduction des obstacles au libre-échange aura une incidence sur l'environnement, car que la production de biens augmente, les méthodes de production sont modifiés et des déchets toxiques sont générés. Au Mexique, les dégâts sont évidents, depuis la qualité diminue de l'air, les rivières polluées, aux endroits où, due à une mauvaise mise en œuvre de la loi, entreprises nationales et internationales détruites le sol et ils polluent le sous-sol avec déchets toxiques. Également dans cet article on va analyser un cas pratique: Metalclad vs Mexique, dans lequel on peut regarder les applications de la réglementation environnementale et des investissements étrangers.

Palabras claves: TLCAN (Tratado de Libre Comercio de América del Norte), Inversiones Extranjeras, ADIE (Arreglo de Diferencias entre Inversionistas y Estados), Medio Ambiente, Arbitraje, CIADI (Centro Internacional de Arreglo de Diferencias Relativas a Inversiones).

Key words: NAFTA (North American Free Trade Agreement), FOREIGN Investments, ISDS (Investor State Dispute Settlement), Environment, Arbitration, ICSID (International Centre for Settlement of Investment Disputes).

Mots clés: ALÉNA (Accord de libre-échange nord-américain), Investissements Etrangers, RDIE (Règlement des Différends entre Investisseurs et États). Environnement, Arbitrage, CIRDI (Centre International pour le Règlement des Différends relatifs aux Investissements).

\section{Introducción.}

EI TLCAN ${ }^{2}$ es un supuesto "tratado de libre comercio" entre los USA, Canadá y México, modelado a partir del Free Trade Agreement (FTA) entre USA y Canadá. Para ser precisos, ningún tratado es de "libre comercio" sino una combinación de nuevas protecciones corporativas, tarifas reducidas y nuevas regulaciones complejas de comercio.

\footnotetext{
${ }^{2}$ Tratado de Libre Comercio de América del Norte, México, Estados Unidos y Canadá. 1 de enero de 1994.
} 
El "libre comercio" en el TLCAN significa que este libera a las corporaciones de las regulaciones de los gobiernos que serían una barrera para comerciar. Básicamente permite el movimiento sin restricciones de dinero, capital, bienes y servicios y al mismo tiempo provee a los inversionistas y a las corporaciones de una extensiva protección de sus derechos de propiedad.

En lo que concierne al ambiente, el TLCAN toma estándares internacionales y reglas que muchas veces son más débiles que las leyes y las regulaciones de México e incluso que las de Canadá y USA. Un ejemplo de esto se ve en el capítulo XI del TLCAN, donde la ley de comercio de EUA, tiene más valor que los tratados internacionales ambientales y también que la habilidad del gobierno de cada país de implementar regulaciones, particularmente en las áreas de medio ambiente y salud.

El Capítulo XI del TLCAN fue diseñado para proteger los intereses de los inversionistas extranjeros con la meta de liberar la inversión internacional. Este capítulo establece además un mecanismo para arreglar las disputas de inversión, este mecanismo pretende lograr la igualdad en el tratamiento de los inversionistas de acuerdo con los principios de la reciprocidad internacional y el debido proceso frente a un tribunal imparcial.

El mecanismo funciona a través de tribunales donde las reuniones son secretas, los miembros son usualmente desconocidos y las decisiones a las que llegan no son enteramente publicadas ${ }^{4}$. Sin embargo, la manera en que estos tribunales manejan las disputas entre los inversionistas y los gobiernos extranjeros han llevado a revocar leyes nacionales y a desafiar regulaciones ambientales, todo en nombre de proteger los derechos de inversionistas extranjeros bajo en TLCAN.

Los inversionistas que crean que han sufrido una pérdida debido a una falta a las reglas del TLCAN pueden llevar su queja contra el gobierno del país donde hicieron su

\footnotetext{
${ }^{3}$ Paúl Gutiérrez, Jesús 'Un área de libre comercio es la modalidad menos avanzada de integración económica, mediante la cual dos o más países eliminan entre ellos obstáculos de todo tipo al comercio de bienes, incluidas las barreras arancelarias, aunque frente al resto del mundo continúan manteniendo cada uno sus propios aranceles".

4 De PALMA, Anthony. "Nafta's Powerful Little Secret; Obscure Tribunals Settle Disputes, but Go Too Far, Critics Say". NYT. (2001)
} 
inversión. Su queja puede ser vista bajo uno de los dos grupos de reglas, uno de las Naciones Unidas y el otro de una institución independiente del Banco Mundial.

El funcionamiento de estos mecanismos autorizados por el Capítulo XI para la resolución de disputas fue lo que me llevo a interesarme por este tema, el hecho de que México haya perdido 5 casos y pagado más de 200 millones de dólares ${ }^{5}$ como compensaciones ante estos tribunales hizo que me surgieran muchas interrogantes. Mi interés aumento al aprender que USA no ha perdido un solo caso de los 20 interpuestos en su contra, de los cuales, solo uno ha sido interpuesto por una asociación mexicana. ¿Es porque ni siquiera nuestros mejores abogados se igualan a los suyos? ¿Por qué firmamos estos tratados de comercio internacional sin negociar mejores términos? ¿Dónde están las autoridades encargadas de defender al país en estos litigios?

La esfera jurídica es muy amplia y siempre hay lugar para mejorar. Es por eso que ningún tema jurídico está agotado. Para poder aprender más del TLCAN nos vamos a auxiliar del derecho internacional y de las normas que aplican a él específicamente, así como a las que aplican en su nivel.

\section{Arbitraje comercial internacional.}

El Arreglo de Diferencias entre Inversionistas y Estados (ADIE), es una provisión que se encuentra comúnmente en los Tratados Bilaterales de Inversión (BIT's) así como en otros Acuerdos Internacionales de Inversión (ADIE). EI ADIE es una forma de resolución de diferencias entre los inversionistas extranjeros y el Estado receptor de sus inversiones.

No cabe duda de que el arbitraje ${ }^{6}$ es el método preferido para el arreglo de diferencias entre los inversionistas extranjeros ya que ofrece flexibilidad, informalidad, ahorro de

5 Sinclair, Scott. "NAFTA Chapter XI Investor-State Disputes to January 1, 2015" Canadian Centre for Policy Alternatives.

${ }^{6}$ José Luis Siqueiros menciona que el arbitraje es "un método o una técnica mediante la cual se tratan de resolver extrajudicialmente las diferencias que puedan surgir entre dos o más partes, mediante la actuación de una o varias personas (árbitro o árbitros), los cuales derivan sus poderes del acuerdo consensual de las partes involucradas en la 
tiempo, la habilidad de elegir la ley sustantiva y procedimental aplicable y la ejecución de las sentencias arbitrales. Sin embargo antes de 1965, no era la norma que este estuviera en los acuerdos de comercio internacional.

La necesidad porque se implementara esta provisión se hizo evidente con los problemas que se daban cuando en los tratados internacionales de inversión no había un acuerdo específico entre el inversionista extranjero y el Estado, las leyes a las que se sometía su inversión serían las locales como lo serian también, las leyes que decidieran sobre los daños que buscara resarcir el inversionista. ${ }^{7}$

En un intento por sobreponer estas dificultades, algunos inversionistas, principalmente de grandes corporaciones, fueron capaces de negociar acuerdos de arbitrajes con los gobiernos anfitriones. Claro, que el número de las corporaciones que estaban en posición de negociar este tipo de acuerdos era muy pequeño, y aun cuando lograban este tipo de acuerdos, su valides podía ser cuestionada, el Gobierno anfitrión se podía negar a proceder con el arbitraje y de nuevo, la única opción que le quedaba al inversionista era pedir la intervención diplomática de su país de origen o porque intercediera por el ante un tribunal internacional. ${ }^{8}$

Ante este panorama surgieron dos posibles soluciones. En la ONU en 1966 se creó la Comisión de las Naciones Unidas para el Derecho Mercantil Internacional (CNUDMI) por la Asamblea General, que dotó a Naciones Unidas de un órgano que le permitía desempeñar una función más activa en la reducción o eliminación de los obstáculos jurídicos que entorpecían el comercio internacional ${ }^{9}$.

Mientras tanto, en el Banco Mundial, donde los Estados capitalistas tenían más poder, se dio forma a una solución diferente. En abril de 1962, los Directores Ejecutivos del banco dedicaron una de sus reuniones a la propuesta de que se creara un Centro para el Arreglo de Disputas relativas a Inversiones a través de un tratado multilateral.

controversia", El arbitraje en los negocios internacionales de naturaleza privada, Editorial Porrúa, México, 1992, p. 7.

7 Note by A. Broches, General Counsel, transmitted to the Executive Directors: "Settlement of Disputes between Governments and Private Parties" in ICSID HISTORY, August 28, 1961.

${ }^{8}$ Op. Cit.

${ }^{9}$ Asamblea General de la ONU, Resolución 2205 (XXI), primera parte. 17 de diciembre de 1966. 


\section{El mecanismo del CIADI.}

El Centro Internacional de Arreglo de Diferencias Relativas a Inversiones (CIADI) es una organización internacional autónoma, sin embargo, tiene vínculos estrechos con el Banco Mundial, todos los miembros del CIADI lo son también del Banco. El objeto del CIADI es:

"La finalidad primordial del CIADI es brindar instalaciones y servicios de soporte para conciliación y arbitraje en diferencias relativas a inversiones internacionales. El arbitraje y la conciliación al amparo del Convenio son totalmente voluntarios y para recurrir a ellos se requiere el consentimiento del inversionista y del Estado de que se trate. Una vez prestado, dicho consentimiento no puede retirarse unilateralmente y se convierte en un compromiso vinculante. EI CIADI es una organización imparcial y no decide los casos. Los árbitros y conciliadores independientes nombrados para cada caso examinan las pruebas y deciden el resultado de las diferencias que se les hayan sometido". ${ }^{10}$

Aunque el CIADI, es la institución principal en materia de arreglo de diferencias relativas a inversiones, México no forma parte de ella, esto es atribuido a la Doctrina Calvo $^{11}$, la cual básicamente mantenía que la jurisdicción en controversias comerciales internacionales se encuentra dentro del país en el cual se localiza la inversión. Carlos Calvo justificaba su doctrina, como necesaria para prevenir el abuso de países más poderosos hacia los más débiles. En este contexto, no solo México era reticente a firmar el Convenio, también lo eran todos los países Latinoamericanos.

\footnotetext{
10 ¿Qué es el CIADI?, https://icsid.worldbank.org/apps/ICSIDWEB/about/Documents 11 La Doctrina Calvo, denominada así por su autor, Carlos Calvo (1824-1906), es una doctrina panamericana de Derecho internacional que establece que, quienes viven en un país extranjero deben realizar sus demandas, reclamaciones y quejas sometiéndose a la jurisdicción de los tribunales locales, evitando recurrir a las presiones diplomáticas o intervenciones armadas de su propio Estado o gobierno. Ha sido recogida en varias constituciones latinoamericanas.
} 


\section{Arreglo de Diferencias entre Inversionistas y Estados según el Capítulo XI del TLCAN.}

Al crearse el TLCAN, uno de sus objetivos era "crear procedimientos eficaces para la aplicación y cumplimiento de este Tratado, para su administración conjunta y para la solución de controversias"12. Por consiguiente, el TLCAN regula tanto las actividades de comercio como las de inversión de los estados miembros. A su vez, el Capítulo $\mathrm{XI}$, trata específicamente con la inversión extranjera. Además provee en su Sección "A" de protecciones a los inversores y a sus inversiones, tales como trato nacional ${ }^{13} \mathrm{y}$ nivel mínimo de trato ${ }^{14}$. $Y$ lo más importante, en su sección "B" contempla la posibilidad de arreglar las diferencias por medio de un mecanismo de arbitraje (el ADIE) directo entre inversores de un Estado parte y otro Estado parte ${ }^{15}$ contra uno de los Estados parte cuando este viole las protecciones a la inversión estipuladas en la Sección "A". Previamente este mecanismo era común en los tratados bilaterales de inversión entre países desarrollados y en vías de desarrollo, pero el TLCAN marcó la primera vez que el ADIE era integrado en un tratado regional de libre comercio. Bajo el Capítulo $\mathrm{XI}$, los inversionistas pueden invocar unilateralmente el ADIE y no están obligados a tratar primero de resolver el problema ante las cortes locales. Cabe mencionar que ningún inversionista puede usar este mecanismo en contra de su propio Estado.

El arbitraje se lleva a cabo siguiendo las reglas del Centro Internacional de Arreglo de Diferencias Relativas a Inversiones (CIADI) o de la Comisión de las Naciones Unidas para el Derecho Mercantil Internacional (CNUDMI). Los casos son resueltos por Tribunales formados por tres miembros; uno elegido por el inversor, uno por el Estado demandado y otro seleccionado de común acuerdo. Las decisiones del Tribunal son finales e inapelables ante las cortes domésticas.

En los primeros años del TLCAN se desconocía el potencial que podría llegar a tener el capítulo XI en los sistemas legales de los estados parte. El propósito original de las protecciones a los inversionistas y a sus inversiones era resguardarlos, de las acciones arbitrarias e irrazonables de los gobiernos. Sin embargo hoy en día este

\footnotetext{
${ }^{12}$ TLCAN, articulo 102. Objetivos. Párrafo 1, fracción e

${ }^{13}$ TLCAN, articulo XI02

${ }^{14}$ TLCAN, articulo XI05

${ }^{15}$ TLCAN, artículos XI16 y XI17
} 
propósito es ignorado. Fueron algunos los abogados que se dieron cuenta del potencial de este Capítulo y como consecuencia, los inversores extranjeros lo comenzaron a usar de una manera estratégica para protegerse a sí mismos de la adopción de nuevas leyes o políticas que pudieran tener un impacto económico en ellos. El Capítulo ha creado y sigue creando controversia por diversas razones que involucran problemas económicos, políticos y legales. El problema más debatido es, que la extraterritorialidad jurídica disminuye la soberanía nacional. Además, debido a la materia de la mayoría de los casos discutidos bajo este Capítulo, las críticas por parte de los ambientalistas han dominado mucho el debate.

\section{Caso Metalclad vs México ${ }^{16}$.}

Metalclad $^{17}$, es una empresa americana que operaba en México a través de su subsidiaria "Ecosistemas Nacionales S.A. de C.V." (ECONSA).

El 23 de enero 1993, obtuvo un permiso federal del Instituto Nacional de Ecología (INE), para construir un confinamiento de desechos peligrosos, en Guadalcázar, San Luis Potosí. Cinco meses después de comenzada la construcción, el municipio de Guadalcázar, informó a Metalclad que estaba operando ilegalmente sin un permiso municipal para construir. Metalclad, presento la solicitud para el permiso y siguió construyendo en lo que se "materializaba" el permiso.

Eventualmente el municipio negó el permiso de construcción a Metalclad, además el entonces Gobernador de San Luis Potosí, justo antes de terminar su mandato, presentó un Decreto Ecológico en el que declaraba un área natural protegida que incluía al predio del confinamiento, negando de esta manera, toda posibilidad de operar el referido confinamiento.

Ante este panorama, ante el Tribunal del CIADI Metalclad presentó violaciones a los artículos $1105^{18}$ (estándar mínimo de trato) y $1110^{19}$ (expropiación) del TLCAN y solicitó compensación.

16 CIADI. METALCLAD CORPORATION Demandante y ESTADOS UNIDOS MEXICANOS Demandado. CASO No. ARB (AF)/97/1 (2000). [en adelante LAUDO]

${ }_{17}$ Metalclad Corporation. Metalclad es una empresa de los Estados Unidos de América, constituida conforme a las leyes de Delaware (1993). 
El Tribunal determinó que a Metalclad se le negó el trato justo y equitativo por parte de México, ya que el gobierno municipal no tenía autoridad para negar el permiso de construcción en bases ambientales y también porque la ausencia de leyes y procedimientos claros en el permiso de construcción municipal equivalía a una falla de

${ }^{18}$ Articulo 1105 tlcan-nafta. Nivel minimo de trato.1. Cada una de las partes otorgara a las inversiones de los inversionistas de otra parte, trato acorde con el derecho internacional, incluido trato justo y equitativo, asi como proteccion y seguridad plenas. 2. Sin perjuicio de lo dispuesto por el parrafo 1, cada parte otorgara a los inversionistas de otra parte y a las inversiones de inversionistas de otra parte, cuyas inversiones sufran perdidas en su territorio debidas a conflictos armados o contiendas civiles, trato no discriminatorio respecto de cualquier medida que adopte o mantenga en relacion con esas perdidas. 3 . El parrafo 2 no se aplica a las medidas existentes relacionadas con subsidios o ventajas que pudieran ser incompatibles con el articulo 1102, salvo por lo dispuesto en el articulo 1108(7) (b).

19 Artículo 1110, tlcan-nafta. Expropiacion e indemnizacion.1. Ninguna de las partes podra nacionalizar ni expropiar, directa o indirectamente, una inversion de un inversionista de otra parte en su territorio, ni adoptar ninguna medida equivalente a la expropiacion o nacionalizacion de esa inversion (expropiacion), salvo que sea: (a) por causa de utilidad publica; (b) sobre bases no discriminatorias; (c) con apego al principio de legalidad y al articulo 1105(1); y (d) mediante indemnizacion conforme a los parrafos 2 a 6. 2. La indemnizacion sera equivalente al valor justo de mercado que tenga la inversion expropiada inmediatamente antes de que la medida expropiatoria se haya llevado a cabo (fecha de expropiacion), y no reflejara ningun cambio en el valor debido a que la intencion de expropiar se conocio con antelacion a la fecha de expropiacion. Los criterios de valuacion incluiran el valor corriente, el valor del activo (incluyendo el valor fiscal declarado de bienes tangibles), asi como otros criterios que resulten apropiados para determinar el valor justo de mercado. 3. El pago de la indemnizacion se hara sin demora y sera completamente liquidable. 4. En caso de que la indemnizacion sea pagada en la moneda de un pais miembro del grupo de los siete, la indemnizacion incluira intereses a una tasa comercial razonable para la moneda en que dicho pago se realice, a partir de la fecha de la expropiacion hasta la fecha de pago. 5. Si una parte elige pagar en una moneda distinta a la del grupo de los siete, la cantidad pagada no sera inferior a la equivalente que por indemnizacion se hubiera pagado en la divisa de alguno de los paises miembros del grupo de los siete en la fecha de expropiacion y esta divisa se hubiese convertido a la cotizacion de mercado vigente en la fecha de expropiacion, mas los intereses que hubiese generado a una tasa comercial razonable para dicha divisa hasta la fecha del pago. 6. Una vez pagada, la indemnizacion podra transferirse libremente de conformidad con el articulo 1109. 7. Este articulo no se aplica a la expedicion de licencias obligatorias otorgadas en relacion a derechos de propiedad intelectual, o a la revocacion, limitacion o creacion de dichos derechos en la medida que dicha expedicion, revocacion, limitacion o creacion sea conforme con el capitulo xvii, "propiedad intelectual". 8. Para los efectos de este articulo y para mayor certeza, no se considerara que una medida no discriminatoria de aplicacion general es una medida equivalente a la expropiacion de un valor de deuda o un prestamo cubiertos por este capitulo, solo porque dicha medida imponga costos a un deudor cuyo resultado sea la falta de pago del adeudo. 
parte de México, para asegurar la transparencia que el TLCAN requiere. El Tribunal también determinó que el Decreto Ecológico por si solo constituía un acto de expropiación.

El Tribunal llegó a la conclusión de que la inversión de Metalclad se había perdido completamente como resultado de las acciones de México y procedió a estimar el valor de la inversión en el mercado. Se determinó que la compensación de ganancias perdidas no era apropiada ya que el confinamiento nunca había entrado en funcionamiento, así, el monto de la compensación se determinó en base a la inversión real hecha por Metalclad, demostrada a través de las declaraciones de impuestos y documentos de auditorías independientes. Los daños se estimaron en EU\$16.7 millones, que también incluía intereses. El Tribunal no proporcionó un desglose de esta cantidad, ni tampoco dió detalles de cómo llegó a ella.

Posteriormente, México apeló la sentencia ante la Suprema Corte de Columbia Británica. En su revisión, la Corte dejó de lado las conclusiones del Tribunal sobre el articulo 1105 (estándar mínimo de trato) y parcialmente las del articulo 1110 (expropiación). Sin embargo, los daños fueron confirmados en base a la expropiación que resultó del Decreto Ecológico. Así, la compensación quedo virtualmente igual, solamente suprimieron los intereses por las supuestas violaciones del gobierno Mexicano, previas al Decreto Ecológico. Eventualmente, se le ordenó a México, pagar US\$15.6 millones más intereses a Metalclad.

\section{Conclusiones.}

Hace 22 años, después de un encendido debate, entró en vigencia el Tratado de Libre Comercio de América del Norte (TLCAN) ${ }^{20}$ entre Estados Unidos, Canadá y México. Aunque en principio el TLCAN fue catalogado como un acuerdo "comercial", gran parte de su contenido se centra en temas de inversiones. El Tratado establece los derechos de los inversionistas extranjeros dentro de los países del TLCAN, respecto de la adquisición, propiedad y operación de las "inversiones" comprendidas en el TLCAN y restringe la capacidad de los gobiernos de legislar y aplicar las normas nacionales a los inversionistas y a sus inversiones.

${ }^{20}$ North American Free Trade Agreement (TLCAN), 1994 
La discusión sobre el TLCAN y lo que representa nunca ha dejado de ser relevante, en la actualidad se pueden escuchar críticas a éste en las campañas de los candidatos a la presidencia de los USA, lo que puede parecer extraño ya que de la parte mexicana y canadiense se podría argumentar que ellos son el país más beneficiado por el TLCAN, sin embargo, visto desde su punto de vista también se puede argumentar que muchos de sus ciudadanos perdieron sus empleos cuando sus compañías se pasaron al sur de la frontera.

Por parte de México las estadísticas dicen que la entrada en vigor del TLCAN trajo consigo muchos empleos ${ }^{21}$, sin embargo, según un informe del Club Sierra en el ámbito ecológico las estadísticas no muestras datos tan favorables; un ejemplo relativo es la gran contaminación de residuos peligrosos (solapada por la ley mexicana) que generan las maquiladoras extranjeras y que no son regresados al lugar de origen de estas, para recibir el tratamiento adecuado. Tan solo el 12\% de las 8 toneladas de residuos peligrosos recibe este tratamiento y solo el $30 \%$ es regresado a su país de origen.

Aunque el gasto para la protección ambiental en México creció entre 1988 y 1993, este cayó casi en una mitad entre 1994 y 1999. El costo de los daños ambientales ha sido en promedio el 10\% del PIB de México desde 1999, equivalente a EU\$64 billones en $2004^{22}$. En 2014 el costo que se tendría que asumir por los daños ambientales disminuyó y fue del $5.3 \%$ del PIB, que equivale a $\$ 910,906$ millones. $^{23}$

Ante este panorama queda claro que nuestro país tiene que intervenir urgentemente y hacer algo para rectificar y prevenir el daño que se le hace a nuestro medio ambiente, claro que para lograrlo se necesitaran políticas firmes y que nuestros gobernantes no cedan ante las presiones de otros países que nos ven débiles. México es un país rico en su tierra y en sus recursos, pero si seguimos ignorando el cuidado al medio ambiente, seguramente que: no tendremos nada que dejarles a las futuras generaciones.

${ }^{21}$ DeLong, Brad. "The same logic that leads us to think that the bilateral U.S. trade deficit from NAFTA has reduced employment in the U.S. by 350,000 leads us to think that it has boosted employment in Mexico by 1.5 million-that's $3 \%$ of the Mexican labor force". Was NAFTA a disaster? 2014.

22 INEGI. Sistema de Cuentas Económicas y Ecológicas de México. 1999-2004

${ }^{23}$ INEGI. Sistema de Cuentas Económicas y Ecológicas de México. 2014. 


\section{Referencias bibliográficas y Webgrafía}

DUGAN, Christopher, WALLACE,Don, RUBINS,Noah, SABAHI,Borzu "Investor-State Arbitration". OUP USA, Nov 25, 2011

CIADI. Convenio sobre arreglo de diferencias relativas a inversiones entre estados $y$ nacionales de otros estados. Capítulo II Jurisdicción del Centro, articulo 25.

CIADI. METALCLAD CORPORATION (2000) Demandante y ESTADOS UNIDOS MEXICANOS Demandado. CASO No. ARB (AF)/97/1.

CIADI. Reglamento del Mecanismo Complementario. Artículo 2: Mecanismo Complementario.

DE PALMA, Anthony. (2001) “Nafta's Powerful Little Secret; Obscure Tribunals Settle

Disputes, but Go Too Far, Critics Say". NYT.

INEGI. Sistema de Cuentas Económicas y Ecológicas de México. 1999-2004 y 2014

PEREZNIETO, CASTRO L, et alius; 1994 EI TLC, Una introducción, ED. Monte Alto y Universidad de Sonora.

PEREZNIETO, CASTRO L. y GRAHAM; "Tratado de Arbitraje Comercial Internacional Mexicano", Colección Mediación -Arbitraje, Ed. LIMUSA, año 2009.

RODRÍGUEZ JIMÉNEZ, Sonia (2013).La incoherencia jurídica y el impacto social del capítulo XI del TLCAN en México" UNAM

SINCLAIR, Scott. "NAFTA Chapter 11 Investor-State Disputes to January 1, 2015" Canadian Centre for Policy Alternatives.

UNITED STATES INTERNATIONAL TRADE COMMISSION. (1990) "Review of trade and investment liberalization measures by Mexico and prospects for future United StatesMéxico relations" Washington D.C.

WORLD BANK. "Settlement of Disputes between Governments and Private Parties" in ICSID HISTORY, August 28, 1961.

\section{Webgrafía}

¿Qué es el CIADI?, Disponible en

https://icsid.worldbank.org/apps/ICSIDWEB/about/Documents (Consultado 10/04/2016) Tratado de Libre Comercio de América del Norte, México, Estados Unidos y Canadá. 1 de enero de 1994. Disponible en http://www.sice.oas.org/trade/nafta/naftatce.asp (Consultado 10/04/2016) 